\title{
Optimal growth under socially responsible investment: a dynamic theoretical model of the trade-off between financial gains and emotional rewards
}

\author{
Orlando Gomes
}

\begin{abstract}
Socially responsible investment (SRI) evolved, along the last two decades, from an almost unexplored topic in science to a recurrent theme of research and debate in Economics and Finance. The growing interest on the theme has two fundamental causes. On one hand, empirical evidence unveils a change of behavior of investors, who typically no longer restrict their decision-making to a strict financial analysis; ethical, social, environmental, and political concerns are also on the forefront of investors' assessments. On the other hand, the economic science is witnessing a paradigm shift characterized by a progressive departure from the orthodox rational deliberation framework and in the direction of the introduction of behavioral elements. In this study, an intertemporal model is proposed to serve as a benchmark for the evaluation of the implications of social and environmental awareness upon investors' decisions and investment performance. The model is a simple optimal control framework that highlights the trade-off between financial returns and the satisfaction emanating from investing in firms or projects guided by ethical values and by good governance principles. Better financial outcomes may come with a social damage that the representative agent in the model will include, with a negative sign, in her utility function. Long-term steady-state results and transitional dynamics are duly evaluated for neoclassical and endogenous growth versions of the model.
\end{abstract}

Keywords: Socially responsible investment, Ethical investment, Warm-glow effect, Intertemporal optimization, Endogenous growth, Transitional dynamics

JEL classification: G41, 041

\section{Introduction}

Along the first two decades of the new millennium, socially responsible investment (SRI) evolved from a marginal and almost unnoticed topic of research in Economics and Finance to a fundamental and unavoidable theme of investigation and debate across the scientific community. Such an assertion is easily backed up by the data. A simple bibliometric exercise confirms this: collecting information from the IDEAS-REPEC database,

Correspondence: omgomes@iscal.ipl.pt

Instituto Superior de Contabilidade e Administração de Lisboa (ISCAL/IPL), Av. Miguel Bombarda 20, 1069-035 Lisboa, Portugal searching for the term 'socially responsible investment' delivers the results presented in Fig. $1^{1}$. The trend unveiled by the figure is unquestionable: the number of publications (published articles, working papers, and book chapters) under the theme of SRI has grown systematically and consistently throughout the mentioned time interval. Today, SRI is present in the scientific literature under a countless number of perspectives, from the empirical estimation of individual investors' socially responsible

\footnotetext{
${ }^{1}$ The IDEAS-REPEC database is the world's largest bibliographic database dedicated to Economics and related scientific fields. According to the information available in the corresponding web site (https://ideas.repec.org), it indexes over 3,200,000 research items, including more than 3,000,000 items
} that can be downloaded in full text. 


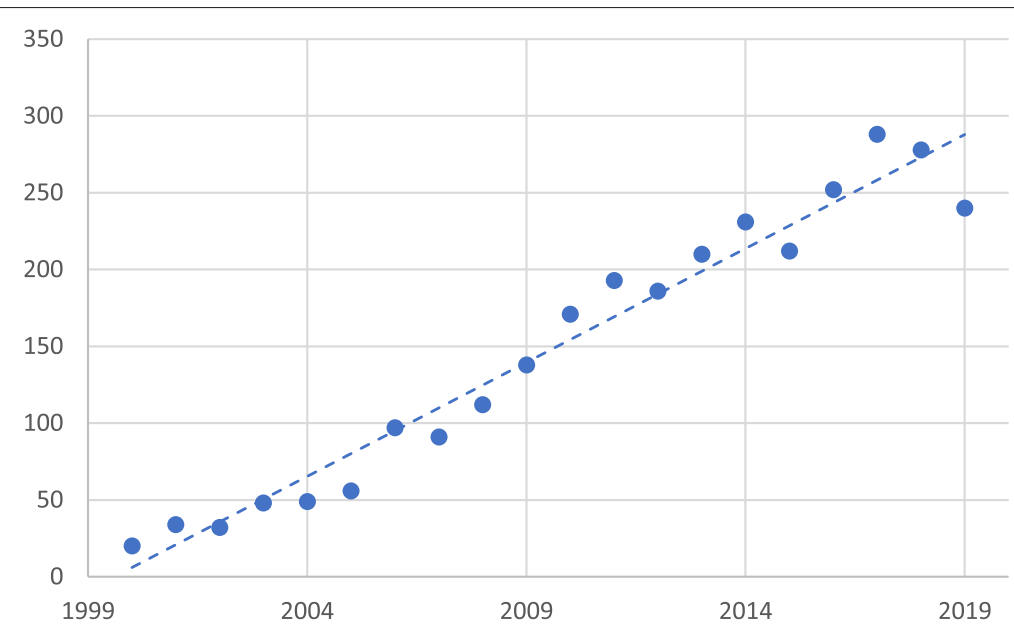

Fig. 1 Number of articles and papers mentioning the term 'socially responsible investment' per year (source: IDEAS-REPEC database, 2000-2019)

behavior to the theoretical evaluation of the macroeconomic consequences of SRI practices.

The reasons underlying the SRI literature outbreak are essentially two: on one hand, the need to study and understand an increasingly relevant empirical phenomenon associated with today's financial practices and, on the other hand, a paradigm shift on economic thinking, which has loosened the orthodox homo-economicus perspective and deviated the focus to the behavioral elements underlying economic and financial decision-making.

Concerning the second point above, one should emphasize that approaching SRI from a scientific point of view is part of a wider movement regarding the surge of behavioral science and of its applications to Economics and Finance $^{2}$. Behavioral Economics constitutes the ideal setting for the discussion about SRI to flourish. Taking SRI as a serious scientific subject requires the recognition that individuals are more than self-interested rational beings, a recognition that is today widespread across the scientific community ${ }^{3}$.

Most of all, however, the curiosity and interest in SRI comes from the observation that investors are, in fact, in many different financial settings, changing the criteria with which they select projects and portfolios in which to invest. In an influential study, Fama and French (2007) highlight that investors exhibit a taste for assets, meaning that they often reveal a preference for one financial asset over the other, despite their return and risk characteristics

\footnotetext{
${ }^{2}$ See, e.g., Shiller (2015) and Thaler (2015).

${ }^{3}$ Holt et al. (2011) and Arthur (2013) claim that the neoclassical Economics era, founded on the orthodoxy of full rationality, is giving place to a new era, which is less strict from the methodological point of view and that might be classified as the era of complexity. Under the novel perspective, economic agents are boundedly rational and may act distinctively when faced with identical scenarios (they are heterogeneous regarding preferences, skills, endowments, and expectations).
}

being, hypothetically, exactly the same. Preferences over assets with identical financial features necessarily mean that agents care about the business or the value-creating activity underlying the investment, and the main criterion to evaluate different projects at this level will then be attached to their environmental, social, political and long-term economic impact.

The literature review in "Literature review: SRI, economic growth, and dynamic modelling" section will explore with additional detail the above mentioned reasons to address SRI as a relevant theme of discussion and analysis in the context of the economic science. The sections that follow will, then, fulfill the main purpose of this study, which is to associate SRI to economic theory through the construction, examination, and discussion of a dynamic optimal control model. The proposed model approaches the trade-off between the productivity advantages that eventually arise when not fully complying with ethical and socially responsible standards and norms, and the utility gain (loss) that comes from the perception of the agent that she is allocating her funds to projects that impact positively (negatively) in society and future generations. The structure of the model to be assembled is mainly inspired in the class of intertemporal choice frameworks that are commonplace in optimal growth literature (Lucas, 1988; Romer, 1990).

Previous theoretical work on the economic implications of SRI includes the contributions of Dam (2011), Dam and Heijdra (2011), Dam and Scholtens (2015), and Renstrom and Spataro (2018). All these contributions consider dynamic settings (overlapping generations models and representative agent infinite horizon intertemporal models) to approach the motivations leading to SRI and its socioeconomic implications. Such frameworks have in common the consideration of a social damage 
variable. Investors want to avoid social damage and they include this desire in their objective functions; some social damage may be unavoidable, though, to guarantee that the expected financial return is obtained. The main novelty in these models consists in the way in which avoiding social damage is modeled. This is done through what the mentioned group of authors designates by warm-glow motive or warm-glow effect: people receive an emotional reward by believing they are investing responsibly, and this emotional reward might be included in the objective function that the agent intends to maximize. The warmglow component in the objective function will increase the perceived value of the returns on SRI or, putting it the other way around, lowers the utility of investment in less socially responsible projects.

The main distinguishing feature of the analysis to undertake in this paper, relatively to the studies mentioned in the above paragraph, is that while such studies consider relatively sophisticated macroeconomic environments, the structure of analysis to adopt in this paper is a simple deterministic optimal growth model, where a single trade-off exists, precisely the trade-off between financial gains and emotional reward. This will allow to discuss in a transparent and straightforward way the direct implications of SRI for intertemporal investment choices. As in the typical optimal growth model, in our environment a representative agent will maximize utility subject to a capital accumulation constraint. However, differently from the standard setup, the consumption-savings tradeoff is overlooked, what is done by considering that the representative agent is a wealthy hand-to-mouth agent that consumes her wage and reinvests all capital returns ${ }^{4}$. By overlooking consumption choices, the model concentrates on the selection of the level of social damage the investor is willing to bear to balance her two goals: to obtain a financial return from her investment and to maintain high her emotional reward attached to the social impact of the investment. The mentioned trade-off is scrutinized under two types of growth settings: a neoclassical growth model and an endogenous growth model that assumes, as the engine of growth, the accumulation of human capital.

The remainder of the paper is organized as follows. "Literature review: SRI, economic growth, and dynamic modelling" section discusses the relevant literature and motivates further the analysis to be undertaken. "The benchmark intertemporal optimization model" section presents the basic structure of the dynamic SRI model. In "Steady-state and transitional dynamics" section, the steady-state and transitional dynamics of the model are addressed. "A two-sector endogenous growth model"

${ }^{4}$ See Kaplan et al. (2014) for a thorough exposition on the economic relevance of wealthy hand-to-mouth agents. section presents and develops a modified version of the framework within a setting of endogenous growth. Finally, "Conclusion" section concludes.

\section{Literature review: SRI, economic growth, and dynamic modelling}

Studies on the increasing relevance and impact of SRI over businesses, financial markets, and the society as a whole, abound in the scientific literature. SRI has been addressed through a variety of angles, including the identification of the motivations of investors, the quantification of explicit and implicit financial returns and other gains, the evaluation of the interplay between SRI and corporate social responsibility, and the assessment of the economy wide impact of the investors' change in attitude towards increased social awareness.

The following non-exhaustive list highlights and systematizes the most significant perspectives and dimensions in which SRI has been approached by scientists working in the academic fields of finance, management, ethics, and economics. It also synthesizes the most meaningful findings of this research.

1. Economic agents are willing to pay a price to be socially responsible, i.e., they are in the disposition of renouncing to part of their financial earnings in order to guarantee that their money is being well spent, from a social responsibility point of view. The non-financial benefit is often referred to, in the mentioned context, as a psychic dividend (Ciciretti et al., 2017, Ainsworth et al., 2018; Lapanan, 2018; van Dooren and Galema, 2018);

2. Investors engage in SRI for two connected but distinct motives. The straightforward motive is the aforementioned taste for assets, i.e., the direct satisfaction or utility emerging from making socially responsible financial decisions. The second motive is purely rational from the financial evaluation perspective and is attached to the exposure to risk: investing in socially responsible projects lowers the risk associated with potential consumer boycotts, environmental scandals, or penalties eventually imposed by regulatory entities (Nakai et al., 2013; Häfner et al., 2017; Tosun, 2017; Rossi et al., 2019);

3. In general, there is no conclusive evidence of under-performance or over-performance of SRI over other kinds of investment. This may be a symptom that social responsible behavior by firms has advantages and disadvantages concerning the capacity to generate value, and that such advantages and disadvantages may roughly cancel each other (contradictory results regarding SRI performance are found when analyzing a series of contributions on the issue, such as the following: Gil-Bazo et al., 2010; 
Rathner, 2012; Latinovic and Obradovic, 2013; Dias Curto and Vital, 2014; Pouget, 2014; Sliwinski and Lobza, 2017; López-Arceiz et al., 2018; Risalvato et al., 2019);

4. There is also evidence pointing out that investors tend to hold diversified portfolios, composed by SRI and conventional investments. Frequently, agents are satisfied by being partially socially responsible, i.e., by including SRI concerns in their savings plans, without nevertheless making this the main driver for their financial decisions (Bello, 2005; Revelli and Viviani, 2015; Miralles-Quirós and Miralles-Quirós, 2017; Oikonomou et al., 2018);

5. It is reasonable to predict that SRI will continue to attract investors, in an age of fast information dissemination, widespread moral judgement, and where specific instruments to measure the degree of social responsibility are becoming more frequently available, as ethical indices and ethical rating agencies that provide credibility to such indices (Petrillo et al., 2016; Risalvato, 2017; Diez-Canamero et al., 2020);

6. SRI became a global phenomenon. Studies report that SRI, and the underlying social, environmental and ethical concerns, are turning into an important component of investment assessment all over the world, in many regions and countries (Lozano et al., 2006 [Spain]; Sakuma and Louche, 2008 [Japan]; Pérez-Gladish et al., 2012 [Australia]; Rathner, 2013 [Austria]; Barca, 2015 [Algeria]; Lean et al., 2015 [Europe and North-America]; Crifo and Mottis, 2016 [France]; Torres and Enciso, 2017 [Mexico]; Klobukowska, 2017 [Asia]);

7. Studies also document that corporate social responsibility increases investment efficiency. This means that ethical behavior by firms is, in fact, an attractor for SRI, and that those who invest in socially responsible projects will be deeply engaged and will show more solidarity with the firms in which they invest. Although acting responsibly has direct financial costs for firms, eventually creating a direct competitive disadvantage, it also has advantages because it increases confidence among the investors, who will invest more and will act more actively to promote the success of the investment (Ghoul and Karoui, 2017; Agudelo et al., 2019; Chatzitheodorou et al., 2019; Tamvada, 2020).

Given the above remarks concerning SRI and its relevance, what items should a SRI definition contemplate in order for it to be a rigorous and comprehensive definition? Also named ethical finance, SRI relates to the decisions of investors which combine financial objectives with concerns about the environment, the society, and governance in general. A socially responsible investor will want to balance the attitudes and actions of managers, the care about the environment, and social issues, against financial performance. A socially responsible investor will want to identify the companies that meet a given standard of corporate social responsibility to partner with them.

There are many possible dimensions involved in SRI. These are highlighted, for instance, in Benlemlih and Bitar (2018), who include in the list of concerns of a responsible investor items as working conditions and employee rights, support to human rights in general, the promotion of diversity, corporate governance, and the preservation of the environment. These authors point out, as well, the existence of activities or industries that by their nature do not constitute a recommendable investment possibility, e.g. alcohol, tobacco, or firearms.

When talking about productive activities that generate social damage, environment is the most evident area where SRI might have a relevant role. Nevertheless, other areas must be also accounted for, namely health and safety working conditions or the way the activity the investment targets is more or less damaging for social cohesion. The areas where SRI is relevant are also the areas where negative externalities tend to exist and, in this way, SRI is an immediate market response to a series of problems that, in a second stage, public authorities might intervene upon. According to Knuutinen and Pietiläinen (2017), public policies aiming at fighting less responsible procedures and actions by firms are perceived by investors as an incentive to continue to pursue themselves an ethical financial behavior.

Furthermore, SRI is the mirror image of corporate social responsibility. As highlighted by Puaschunder (2017), firms are socially responsible in the sense they try to capture investment and for such they need to act in a responsible way. Acting responsibly will certainly contribute for a future strategic advantage. In Revelli's (2017) view, announcing that an investment is socially responsible is a way to call the attention of investors. This also has its perils, because firms become socially responsible not because of a genuine concern with society and the environment but because they opportunistically perceive that this might bring about the curiosity and attention of investors and their willingness to take part in the business.

The discussion in the precedent paragraphs reveals a theme that has wide ramifications, which spread throughout many areas of knowledge within business sciences and social sciences. Specifically, in this study and in the sections that follow, SRI is approached from the economic theory point of view. The trade-off between financial and non-financial returns is evaluated and debated, assuming for such the structure of an optimal growth model. This 
is a relatively simple theoretical framework that allows to analyze the mentioned trade-off in a dynamic (i.e., intertemporal) perspective.

Optimal growth theory typically concentrates attention on the supply side of the economy, i.e., on the accumulation of wealth through the efficient use and combination of factor inputs. Behavioral elements are, in general, excluded from the analysis; they rarely emerge in this type of setting where almost invariably a representative agent maximizes consumption utility subject to resource accumulation constraints. One behavioral element emerges, though, when taking into account agent heterogeneity; nevertheless, in growth models heterogeneity is typically circumscribed to supply-side issues, namely concerning skills, productivity and innovative capabilities (Kim and Song, 2014; Zeira and Zoabi, 2015; Jaimovich and Rebelo, 2017; Acemoglu et al., 2018; Akcigit and Kerr, 2018; Grossman and Helpman, 2018). In Altman (2009), technological change is perceived as a behavioral and institutional phenomenon.

Other types of heterogeneity and non-standard behavior, namely concerning agents' preferences, are seldom integrated in this kind of structure of analysis. Exceptions are rare. One of these exceptions is the work by Jones (2016). By building a growth framework that associates the pace of economic growth with fundamental choices on how to produce, Jones (2016) indirectly tackles with the issue of SRI. The main argument offered by this author is that the economy and its agents systematically have a crucial decision to make: to grow slow and safe, or to grow fast and recklessly. Several possible examples of this type of dilemma are given in the cited study and include producing automobile engines that pollute less vs producing automobile engines that are more powerful, or manufacturing insulating material that is safer vs manufacturing insulating material that is easier to produce. As it should be evident, when the society (the investors) decides about the posed choices, it is also selecting the level of SRI that is sensible to pursue under given socioeconomic conditions. In a same vein, Antoci et al. (2012) make an integrated approach of environmental degradation and economic growth, by establishing an individual preference for the decision-maker regarding long-term natural protection.

The model to explore in the next sections puts the emphasis in the aforementioned kind of dilemma, where not only quantitative growth but also qualitative growth matters: the emphasis is placed not just on how much to produce but also on how it is produced and on the extent of the externalities that the investment generates.

\section{The benchmark intertemporal optimization model}

Consider a representative investor ${ }^{5}$. As a first simplifying assumption, let this investor be a wealthy hand-to-mouth agent (as defined in Kaplan et al., 2014), i.e., someone who, at every date $t$, fully consumes her labor income and re-invests all capital returns. This rule-of-thumb interpretation of the agent's behavior allows us to concentrate solely on investment decisions, thus overlooking the prior consumption-savings allocation problem.

The investor faces a wide array of investment opportunities, from which she will select, at date $t$, only one. The main selection criterion is associated with the trade-off between the return on the investment and the perception about the extent in which such investment is socially responsible. A fundamental feature of the proposed setup is that an investment project that fails in complying with environmental norms, fiscal obligations, ethical values, labor safety procedures, and other aspects of socially responsible behavior, gains a productivity advantage, in the sense that it may generate additional income with lower costs relatively to other projects where such values and norms are respected. As such, when selecting an investment project, the investor is essentially choosing the degree of social damage she is willing to bear in order to keep investment returns high or, conversely, how much income she is willing to abdicate to act in a socially responsible mode.

Let $D(t) \geq 0$ be a measure of the social damage associated with a given project. If the project fulfills all the criteria to be considered a fully socially responsible investment, then $D(t)=0$. On the other extreme, projects not complying with any of the norms allowing to classify them as socially responsible will be such that $D(t) \rightarrow \infty$. The productivity advantage of socially irresponsible projects is modelled in the following way. Let $A(t) \geq 0$ represent the total factor productivity (TFP) of a given income generating activity; the relation between variables $D(t)$ and $A(t)$ will be such that

$$
A(t)=\frac{A_{l}}{\phi}\left[1-(1-\phi) e^{-D(t)}\right], A_{l}>0 ; 0<\phi \leq 1
$$

In Eq. (1), breaking the norms underlying a socially responsible behavior makes TFP to approach an upper

\footnotetext{
${ }^{5}$ The model is designed and solved for a representative investor, under the implicit assumption that agent heterogeneity is inexistent or negligible. If the agents in the economy all behave in the same rational way, have the same preferences, and possess identical initial endowments, then it is reasonable to analyze the behavior of a single agent as if it was representing the whole set of investors in the economy. This is a typical assumption in economic theory.
} 
bound $A(t)=\frac{A_{l}}{\phi}$; ethical, sustainable and responsible behavior has a cost from the point of view of the project's return, with productivity falling towards the lower bound $A(t)=A_{l}$. The lower the value of parameter $\phi$, the stronger will be the stimulating effect of the socially irresponsible behavior of the project's managers over the capacity of the project to generate a large return.

The production technology associated with projects at each social damage level is identical, and given by a typical Cobb-Douglas production function:

$$
y(t)=A(t) k(t)^{\alpha}
$$

In Eq. (2), $y(t) \geq 0$ and $k(t) \geq 0$ correspond, respectively, to the amounts of output and of physical capital per unit of labor; $\alpha \in(0,1)$ is the output-capital elasticity. Under a competitive market environment, the gross rate of return on investment is equal to the marginal productivity of capital, i.e.,

$$
r(t)=\alpha A(t) k(t)^{-(1-\alpha)}
$$

Because the representative agent integrally reinvests the obtained capital returns, the respective capital accumulation constraint might be displayed as

$$
\dot{k}(t)=[r(t)-\delta] k(t), k(0)=k_{0} \text { given }
$$

with $\delta \in(0,1)$ the capital depreciation rate; $r(t)-\delta$ is the net rate of return on investment.

As the rational agent she is, the representative investor will want to maximize her financial gains. Nevertheless, social responsibility considerations are, in the current context, also an element to take into account in the deliberative process. Without such considerations, the investor would want to attain the highest possible return from the investment, and therefore social damage would be allowed to extend to its fullest; the project(s) for which $D(t) \rightarrow \infty$ would be chosen. However, if social concerns are part of the investor's agenda, the agent will accept lower $A(t)$ and $r(t)$, to guarantee a not so high $D(t)$. Hence, the fundamental question is how much social damage the investor is willing to tolerate in order to boost the productivity of the invested capital.

The benchmark model will involve two endogenous variables: a state variable, the capital stock, and a control variable, which will reflect social awareness or social responsibility. This second variable will be modeled along the lines of the reasoning by Dam and Heijdra (2011) and Dam and Scholtens (2015), i.e., assuming a warmglow motive. Under this motive or effect, the agent draws relatively lower utility if investing in projects involving stronger social damage, i.e., the investor experiences an emotional penalty whenever her investment somehow contributes to environmental, social or political degradation. In opposition, investment projects highly engaged in protecting environmental, social and political norms and institutions will make the investor experience a positive emotional reward that goes beyond the financial gain.

Let $g(t)$ be the warm-glow variable, such that,

$$
g(t)=\frac{1}{\zeta} e^{-D(t)}, 0<\zeta \leq 1
$$

A straightforward inspection of the mathematical properties of Eq. (5) allows to verify that this is a negatively sloped continuous function, with $g(t)=\frac{1}{\zeta}$ for $D(t)=0$ and $g(t) \rightarrow 0$ whenever $D(t) \rightarrow \infty$. Variable $g(t)$ translates the extent to which the representative agent values the financial gain obtained from the investment, for investment opportunities with different attached social damage. There will be a threshold value such that $g(t)=1$, that corresponds to the circumstance in which the social damage is such that the agent does not experience either an emotional reward or an emotional penalty. Under the proposed functional specification, (5), this threshold corresponds to point $D(t)=-\ln \zeta$. If $D(t)>-\ln \zeta$, then $g(t)<1$, implying a utility drawn from the investment that is lower than the financial reward; if $D(t)<-\ln \zeta$, then $g(t)>1$, what signifies that the social damage caused by the economic activity underlying the investment is small enough to justify an increase in perceived utility relatively to the benchmark value, and thus a utility level above the respective financial return.

The above argument is better understood when assembling an explicit utility function, associated with the investment undertaken at date $t$, where utility emanates from the capital income generated by the investment, duly weighted by the warm-glow effect, i.e.,

$$
V(t)=\alpha y(t) g(t)=r(t) k(t) g(t)
$$

Observe that a high value of parameter $\zeta$ (near $\zeta=$ 1) reflects a strong warm-glow effect or a strong social responsibility awareness, in the sense that the emotional penalty over large social damage is high and the emotional reward over small social damage is low. In the opposite case ( $\zeta$ close to zero), the agent experiences a large degree of satisfaction for low levels of social irresponsibility and a small degree of intolerance with respect to high levels of social damage. Figure 2 displays warm-glow function $g(t)$ for different values of parameter $\zeta$.

The intertemporal optimal control problem faced by the representative investor takes the form

$$
\underset{g(t)}{\operatorname{Max}} \int_{0}^{\infty} V(t) e^{-\rho t} d t \text { subject to (4) }
$$

In expression (7), $\rho \geq 0$ is the utility discount rate, or rate of intertemporal preference. Although simple in its structure, the proposed optimal control problem involves relatively intricate dynamics, which are explored in the following section. 


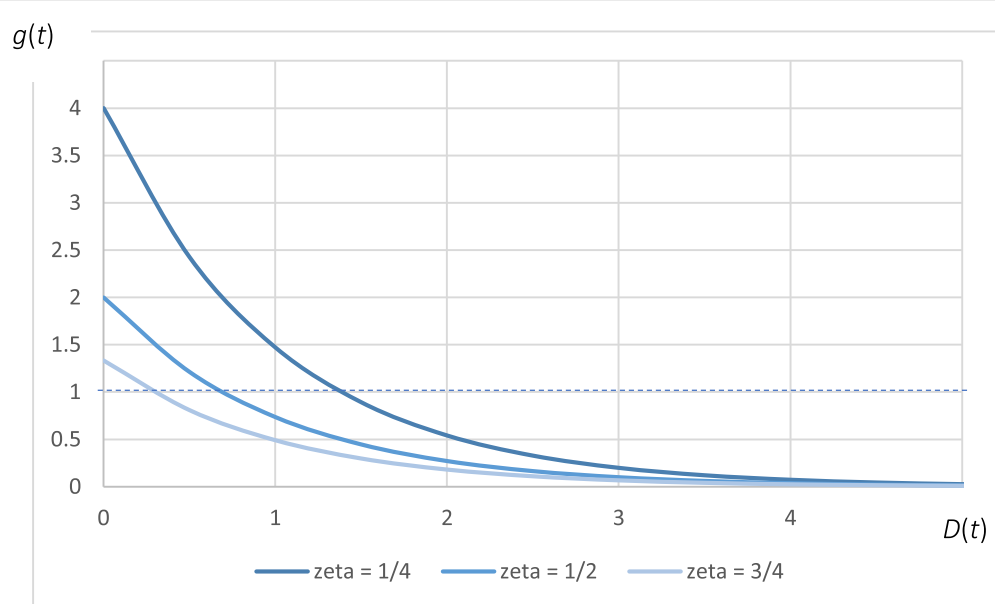

Fig. 2 Warm-glow function $g(t)$

Given Eqs. (1) and (5), one can suppress the social damage variable from the analysis, and establish a straightforward relation between TFP and the social responsibility variable,

$$
A(t)=\frac{A_{l}}{\phi}[1-(1-\phi) \zeta g(t)]
$$

In accordance with Eq. (8), the relation between $A(t)$ and $g(t)$ is of opposite sign: stronger social damage simultaneously increases $A(t)$ and increases social awareness [lowers $g(t)$ ]. Figure 3 represents the relation between variables $A(t)$ and $g(t)$ for different values of parameter $\zeta$; the graphic allows to verify that the lower-bound on the value of the warm-glow variable, $g(t)=0$, is coincidental with the upper-bound on the productivity variable,
$A(t)=\frac{A_{l}}{\phi}$; while the upper-bound on $g(t), g(t)=\frac{1}{\zeta}$, corresponds to the no social damage circumstance such that $A(t)=A_{l}$.

The specified problem is specially meaningful if an interior optimum exists, i.e., if the maximum of $V(t)$ in Eq. (6) is found for a level of $g(t)$ such that $0<g_{\max }<\frac{1}{\zeta}$. Proceeding with the proper computation, one verifies that

$$
\frac{\partial V(t)}{\partial g(t)}=0 \Rightarrow g_{\max }=\frac{1}{2(1-\phi) \zeta}
$$

To guarantee that the found $g_{\max }$ stays within the boundaries of the stipulated interval, the following constraint must hold: $\phi<1 / 2$. This constraint on the value of parameter $\phi$ guarantees that expression (6) will be an inverted U-shaped curve in the $g(t)-V(t)$ space, for every

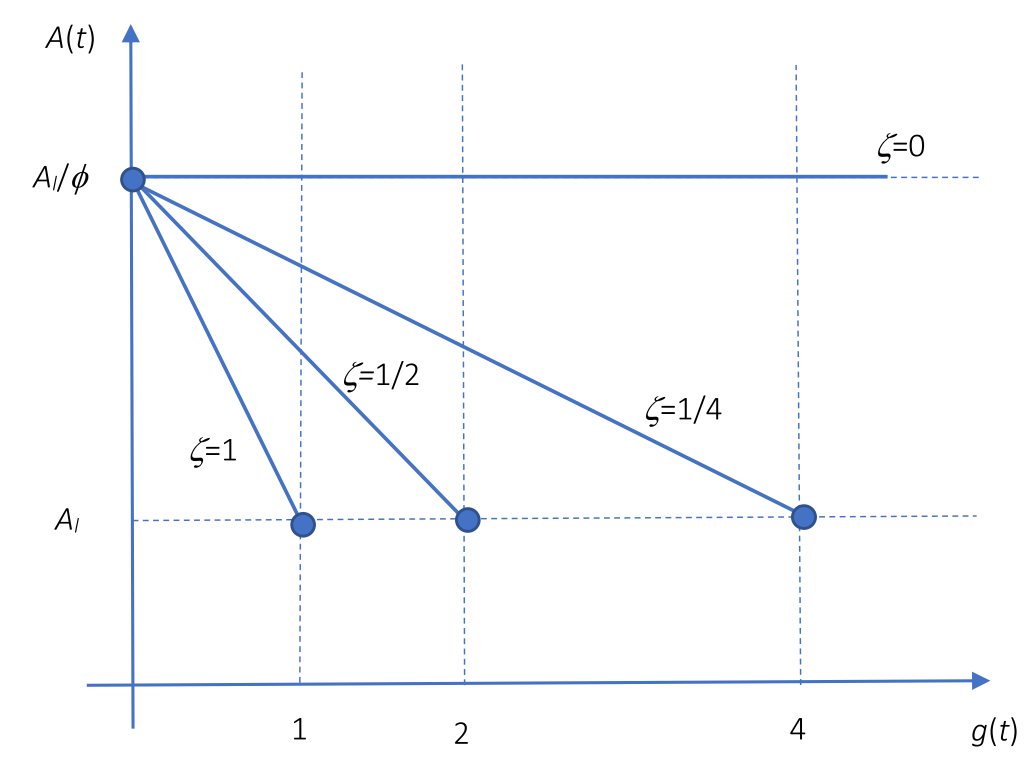

Fig. 3 The $A(t)-g(t)$ diagram 
date $t$, with a maximum inside interval $\left(0, \frac{1}{\zeta}\right)$. If condition $\phi<1 / 2$ is not satisfied, then a radical investor choice will take place: the agent will invariably select an investment project that causes no social damage, although this generates the lowest possible productivity and return. In other words, if the productivity advantage originating on social damaging behavior is not strong enough (i.e., if $\phi$ is not small enough), the investor will prefer to put her money in a completely damage free project.

\section{Steady-state and transitional dynamics}

The first step in the dynamic analysis of optimal control problem (7) consists in displaying the respective currentvalue Hamiltonian function. This is,

$$
H[k(t), g(t), p(t)]=\{r(t)[g(t)+p(t)]-\delta p(t)\} k(t)
$$

with costate variable $p(t) \in \mathbb{R}$ representing the currentvalue shadow-price of capital ${ }^{6}$.

To obtain the first-order optimality conditions, one applies Pontryagin's principle. The conditions are:

$$
\begin{gathered}
\frac{\partial H[.]}{\partial g(t)}=0 \Rightarrow g(t)=\frac{1}{2}\left[\frac{1}{(1-\phi) \zeta}-p(t)\right] \\
\dot{p}(t)=\rho p(t)-\frac{\partial H[.]}{\partial k(t)} \Rightarrow \\
\dot{p}(t)=(\rho+\delta) p(t)-\alpha r(t)[g(t)+p(t)]
\end{gathered}
$$

and the transversality condition,

$$
\lim _{t \rightarrow \infty} p(t) e^{-\rho t} k(t)=0
$$

A differential equation for variable $g(t)$ is obtainable by differentiating Eq. (11) with respect to time,

$$
\begin{aligned}
& \dot{g}(t)=-\frac{1}{2} \dot{p}(t) \Rightarrow \\
& \dot{g}(t)=\frac{1}{2}\{\alpha r(t)[g(t)+p(t)]-(\rho+\delta) p(t)\}
\end{aligned}
$$

In the current setting, under production technology (2), capital accumulation exhibits diminishing marginal returns, what necessarily implies that the stock of capital held by the investor converges to a constant long-term steady-state value. The steady-state will be further characterized by constant levels of productivity, social damage and social awareness. Once the steady-state is asymptotically reached, the long-term optimal choice of the investor is perpetuated over time (in the absence of external disturbances). The long-term optimal choice will correspond to the selection of a specific project in which to invest; this project generates the level of social damage that allows for the best possible combination of potential to

${ }^{6}$ Note that $p(t) \equiv \tilde{p}(t) e^{\rho t}$, with $\tilde{p}(t)$ the present-value costate variable or dynamic Lagrange multiplier (see Barro and Sala-i-Martin, 2004). generate financial returns and mitigation of the ethical concerns posed by the investment option. Finding the long-run optimal levels of social damage, productivity, capital holdings, and emotional reward / emotional penalty over financial returns is the task ahead.

To fully characterize the long-term equilibrium, first observe that, from equation (4), the steady-state rate of return on capital is $r^{*}=\delta$. Applying this equality to $\dot{g}(t)=0$, the following outcome is obtained,

$$
g^{*}=\frac{\rho+\delta-\alpha \delta}{2(\rho+\delta)-\alpha \delta} \frac{1}{(1-\phi) \zeta}
$$

For boundary $g^{*}<\frac{1}{\zeta}$ to be satisfied under (15), one would need to impose constraint $\phi<\frac{\rho+\delta}{2(\rho+\delta)-\alpha \delta}$; this constraint is less restrictive than the already stated condition $\phi<1 / 2$, and thus the obtained result is a feasible interior solution. Expression (15) is instrumental to compute the steady-state levels of productivity, physical capital, and social damage. These are, respectively,

$$
\begin{aligned}
A^{*} & =\frac{\rho+\delta}{2(\rho+\delta)-\alpha \delta} \frac{A_{l}}{\phi} \\
k^{*} & =\left[\frac{\alpha}{\delta} \frac{\rho+\delta}{2(\rho+\delta)-\alpha \delta} \frac{A_{l}}{\phi}\right]^{1 /(1-\alpha)} \\
D^{*} & =-\ln \left[\frac{\rho+\delta-\alpha \delta}{2(\rho+\delta)-\alpha \delta} \frac{1}{(1-\phi)}\right]
\end{aligned}
$$

A relatively detailed characterization of the impact of changes on parameter values over the steady-state locus is made further below for parameters $\zeta$ and $\phi$, which are the ones that determine the shape of the warm-glow function and of the productivity function. A first glance on long-run equilibrium results allows to highlight a few meaningful outcomes: first, the shape of the warm-glow function determines the steady-state value of the warmglow variable but has no impact on the long-term levels of productivity, capital stock, and social damage; second, the value of parameter $\phi$ influences all steady-state results: an increase in the value of $\phi$ will provoke a fall in the steadystate levels of productivity and capital accumulation; the warm-glow index will suffer, in such circumstance, an increase. The optimal level of social damage will fall with an increase in the value of $\phi$. This last result is justified under the logic that if social damage allows more intensely for higher productivity, then the investor might prefer to choose a less damaging level of productivity, thus attributing more weight to the alternative goal of acting responsibly. Note, as well, that a positive change on the discount rate and on the capital depreciation rate will make the value of $D^{*}$ to fall: strong intertemporal discounting and fast capital depreciation imply that the agent will not be willing to accept investing in activities with a high associated social damage. 
Next, we analyze transitional dynamics. The linearization of differential Eqs. (4) and (14) in the steady-state vicinity allows to write the following matricial system,

$\left[\begin{array}{c}\dot{k}(t) \\ \dot{g}(t)\end{array}\right]=\left[\begin{array}{cc}-(1-\alpha) \delta & -\delta(1-\phi) \zeta \frac{2(\rho+\delta)-\alpha \delta}{\rho+\delta} k^{*} \\ -\frac{1}{2} \frac{\alpha(1-\alpha) \delta}{(1-\phi) \zeta} \frac{\rho+\delta}{2(\rho+\delta)-\alpha \delta} \frac{1}{k^{*}} & \rho+(1-\alpha) \delta\end{array}\right] \cdot\left[\begin{array}{c}k(t)-k^{*} \\ g(t)-g^{*}\end{array}\right]$

The trace and the determinant of the Jacobian matrix in system (19), $J$, are, respectively, $\operatorname{Tr}(J)=\rho>0$ and $\operatorname{Det}(J)=-(1-\alpha) \delta\left[\rho+\left(1-\frac{\alpha}{2}\right) \delta\right]<0$. A positive trace and a negative determinant imply that one and only one of the eigenvalues of matrix $J$ is a negative value, meaning that the two-dimensional system under scrutiny is saddlepath stable, i.e., there is one stable dimension. This is the common result in two-dimensional optimal growth models; given the existence of a state variable and of a control variable, the convergence to the steady-state is guaranteed by the possibility of adjustment of the initial value of the control variable to the stable trajectory, which will then be followed as the endogenous variables converge to the already characterized long-term equilibrium locus. Eigenvalues are given by the following expression:

$$
\lambda_{1}, \lambda_{2}=\frac{\rho}{2} \pm\left\{\left(\frac{\rho}{2}\right)^{2}+(1-\alpha) \delta\left[\rho+\left(1-\frac{\alpha}{2}\right) \delta\right]\right\}^{1 / 2}
$$

with $\lambda_{1}<0$ and $\lambda_{2}>0$. To compute the saddle (stable) trajectory and the anti-saddle (unstable) trajectory, one calculates the following eigenvectors' matrix of $J$,

$$
P=\left[\begin{array}{cc}
1 & 1 \\
\frac{1}{2} \frac{\alpha(1-\alpha) \delta}{(1-\phi) \zeta} \frac{\rho+\delta}{2(\rho+\delta)-\alpha \delta} \frac{1}{k^{*}} & -\frac{(1-\alpha) \delta+\lambda_{2}}{\delta+(1-\alpha) \delta-\lambda_{1}}
\end{array}\right]
$$

The saddle-path trajectory is, then, expressed under the form

$$
g(t)-g^{*}=\frac{\frac{1}{2} \frac{\alpha(1-\alpha) \delta}{(1-\phi) \zeta} \frac{\rho+\delta}{2(\rho+\delta)-\alpha \delta} \frac{1}{k^{*}}}{\rho+(1-\alpha) \delta-\lambda_{1}}\left[k(t)-k^{*}\right]
$$

while the anti-saddle trajectory is

$$
g(t)-g^{*}=-\frac{(1-\alpha) \delta+\lambda_{2}}{\delta(1-\phi) \zeta \frac{2(\rho+\delta)-\alpha \delta}{\rho+\delta} k^{*}}\left[k(t)-k^{*}\right]
$$

Clearly, the stable trajectory and the unstable trajectory displayed in Eqs. (22) and (23) are, respectively, positively sloped and negatively sloped. This result might also be depicted graphically, through a phase diagram. Taking the elements in the Jacobian matrix of system (19), note that

$\dot{k}(t)=0 \Rightarrow g(t)-g^{*}=-\frac{1-\alpha}{(1-\phi) \zeta \frac{2(\rho+\delta)-\alpha \delta}{\rho+\delta} k^{*}}\left[k(t)-k^{*}\right]$ $\dot{g}(t)=0 \Rightarrow g(t)-g^{*}=\frac{\frac{1}{2} \frac{\alpha(1-\alpha) \delta}{(1-\phi) \zeta} \frac{\rho+\delta}{2(\rho+\delta)-\alpha \delta} \frac{1}{k^{*}}}{\rho+(1-\alpha) \delta}\left[k(t)-k^{*}\right]$

Curve (24) has a negative slope and curve (25) displays a positive slope. To visualize the location of the saddle and of the anti-saddle trajectories, we now identify directional arrows; these can be drawn in the phase diagram by evaluating the derivatives of the two differential equations with respect to the variable in the horizontal axis, i.e., through the analysis of the values in the first column of the Jacobian matrix in (19). To the right of $\dot{k}(t)=0$, the value of $k(t)$ falls, given that the element in the first row and first column of matrix $J$ is negative; to the left of this reference line, the value of this variable rises (these flows are represented by parallel lines to the axis corresponding to the state variable). Given that the element of matrix $J$ in the first column and second line is also negative, to the right of $\dot{g}(t)=0$ there will be a decrease in the value of $g(t)$, and to the left of this line the opposite will occur (this vector field is represented in parallel to the axis of the control variable).

Figure 4 represents the phase diagram, constructed under the above guidelines. We find that the unstable trajectory is steeper than $\dot{k}(t)=0$; one also confirms that the saddle trajectory is positively sloped, but flatter than $\dot{g}(t)=0$. Since variables will follow the stable trajectory in the direction of the steady-state, and assuming that capital accumulates over time, so that $k(t)$ increases as it converges to the long-term equilibrium, the value of $g(t)$ will also increase along this convergence process, meaning that the emotional reward effect becomes increasingly accentuated.

A final appointment to be made in this section concerns the formal analysis of disturbances over parameter values in the SRI model.

The proposed model involves various parameters. In order to address how the computed steady-state might be disturbed, we concentrate attention on two of these, those with the most direct link with the investment return - responsible investment trade-off: the extent in which departing from a socially responsible investment boosts productivity, $\phi$, and the measure of the warm-glow effect, $\zeta$. We extend the presentation of system (19) in order to include possible perturbations on each of the two highlighted parameters,

$$
\left[\begin{array}{l}
\dot{k}(t) \\
\dot{g}(t)
\end{array}\right]=J \cdot\left[\begin{array}{l}
k(t)-k^{*} \\
g(t)-g^{*}
\end{array}\right]+\left[\begin{array}{cc}
j_{k \phi} & j_{k \zeta} \\
j_{g \phi} & j_{g \zeta}
\end{array}\right]\left[\begin{array}{c}
\Delta \phi \\
\Delta \zeta
\end{array}\right]
$$

with $j_{k \phi}=\frac{\partial \dot{k}(t)}{\partial \phi}, j_{k \zeta}=\frac{\partial \dot{k}(t)}{\partial \zeta}, j_{g \phi}=\frac{\partial \dot{g}(t)}{\partial \phi}, j_{g \zeta}=\frac{\partial \dot{g}(t)}{\partial \zeta}$. To find short-run and long-run multipliers, which represent the changes the endogenous variables go through when 


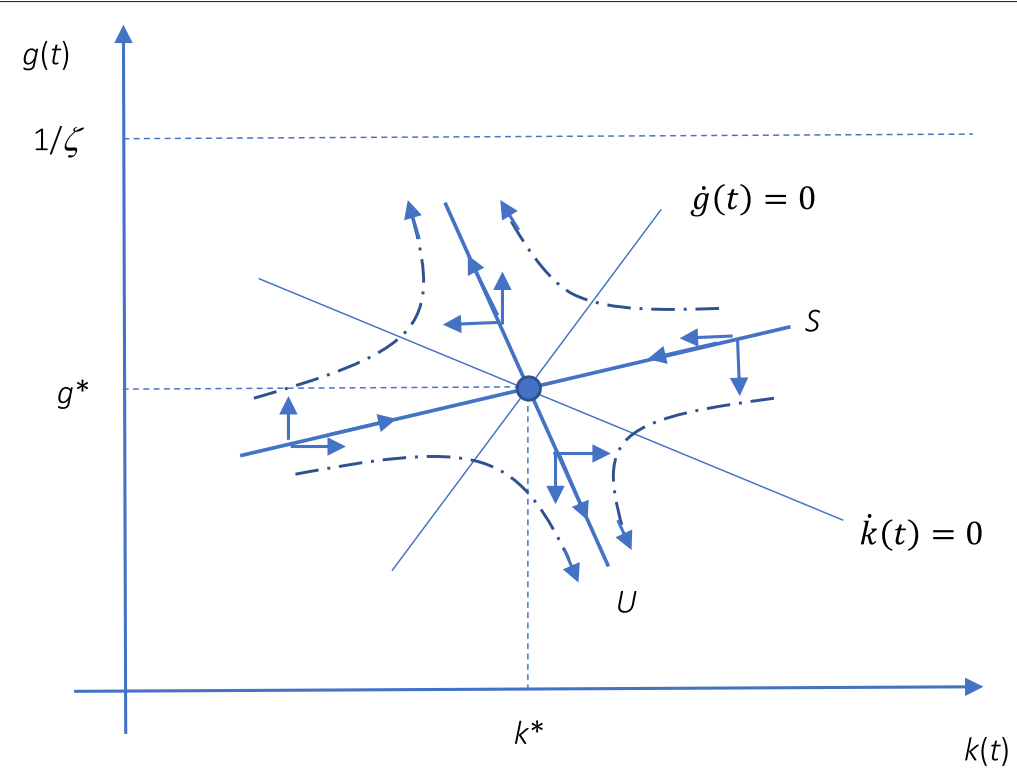

Fig. 4 Phase diagram

the steady-state is disturbed by a change in a parameter value, one needs to compute the inverse of the Jacobian matrix. The long-run multipliers originating from a perturbation on the selected parameters are, then, given by

$$
\left[\begin{array}{l}
\Delta k(\infty) \\
\Delta g(\infty)
\end{array}\right]=-J^{-1}\left[\begin{array}{ll}
j_{k \phi} & j_{k \zeta} \\
j_{g \phi} & j_{g \zeta}
\end{array}\right]\left[\begin{array}{l}
\Delta \phi \\
\Delta \zeta
\end{array}\right]
$$

The following results are the outcome of this computation:

$$
\left[\begin{array}{c}
\Delta k(\infty) \\
\Delta g(\infty)
\end{array}\right]=\left[\begin{array}{cc}
-\frac{1}{1-\alpha} \frac{1}{\phi} k^{*} & 0 \\
\frac{1}{1-\phi} g^{*} & -\frac{1}{\zeta} g^{*}
\end{array}\right]\left[\begin{array}{c}
\Delta \phi \\
\Delta \zeta
\end{array}\right]
$$

System (28) reveals that a perturbation of positive sign on $\zeta$ generates a decrease in the steady-state value of the warm-glow variable $g(t)$, while the capital stock remains unchanged; a positive perturbation in the value of parameter $\phi$ has a negative effect over the capital stock and a positive effect over the warm-glow index, as already highlighted above. Besides the long-term impact, it is also possible to compute the extent of the initial jump in the control variable after the perturbation that allows the system to adjust to locate in the new post-perturbation saddle-path trajectory; while the state variable, capital, does not suffer any initial change, the control variable will be subject to the following jump:

$$
\Delta g(0)=\Delta g(\infty)-\frac{\frac{1}{2} \frac{\alpha(1-\alpha) \delta}{(1-\phi) \zeta} \frac{\rho+\delta}{2(\rho+\delta)-\alpha \delta} \frac{1}{k^{*}}}{\rho+(1-\alpha) \delta-\lambda_{1}} \Delta k(\infty)
$$

with the fraction that multiplies with $\Delta k(\infty)$ being the slope of the saddle-path trajectory, as already displayed in (22). For $\Delta \phi>0$, it is straightforward to identify that
$\Delta g(0)>\Delta g(\infty)$, meaning that the initial jump in the value of the warm-glow variable is stronger than the longterm effect, i.e., there is a shift to the new saddle-path trajectory, which is positively sloped and, once in the new stable trajectory, there is then a fall in the value of both endogenous variables towards the new steady-state point. Note, as well, that the slope of the saddle-path trajectory increases whenever $\Delta \phi>0$; to confirm this, just compute the derivative of the slope with respect to $\phi$ and observe that it possesses a positive sign. For $\Delta \zeta>0, \Delta g(0)=$ $\Delta g(\infty)$ because $k^{*}$ suffers no change and, therefore, in this case, the initial jump in the warm-glow variable that places the system in the new stable trajectory also places it immediately in the new steady-state point.

Figures 5 and 6 display the outcome of the mentioned perturbations. In the first case, the saddle-path shifts upward to the left, leading to a new equilibrium point where $k^{*}$ is smaller than the initial level, and $g^{*}$ is higher. In the instant in which the perturbation occurs, the control variable suffers a jump in the direction of the new stable trajectory; as one can visualize and as already argued, the initial change in $g(t)$ is larger than the final change, because following the new stable trajectory implies that the values of both endogenous variables will decline. In the second case, the saddle-path shifts down, but immediately to the new steady-state point, without the need for any additional adjustment over the new saddle trajectory. The phase diagrams in Figs. 5 and 6 are complemented with the representation of the warm-glow function, in order to visualize how the social damage - warm-glow relation is eventually disturbed: a positive change in the value of $\phi$ does not provoke any effect on the location of 

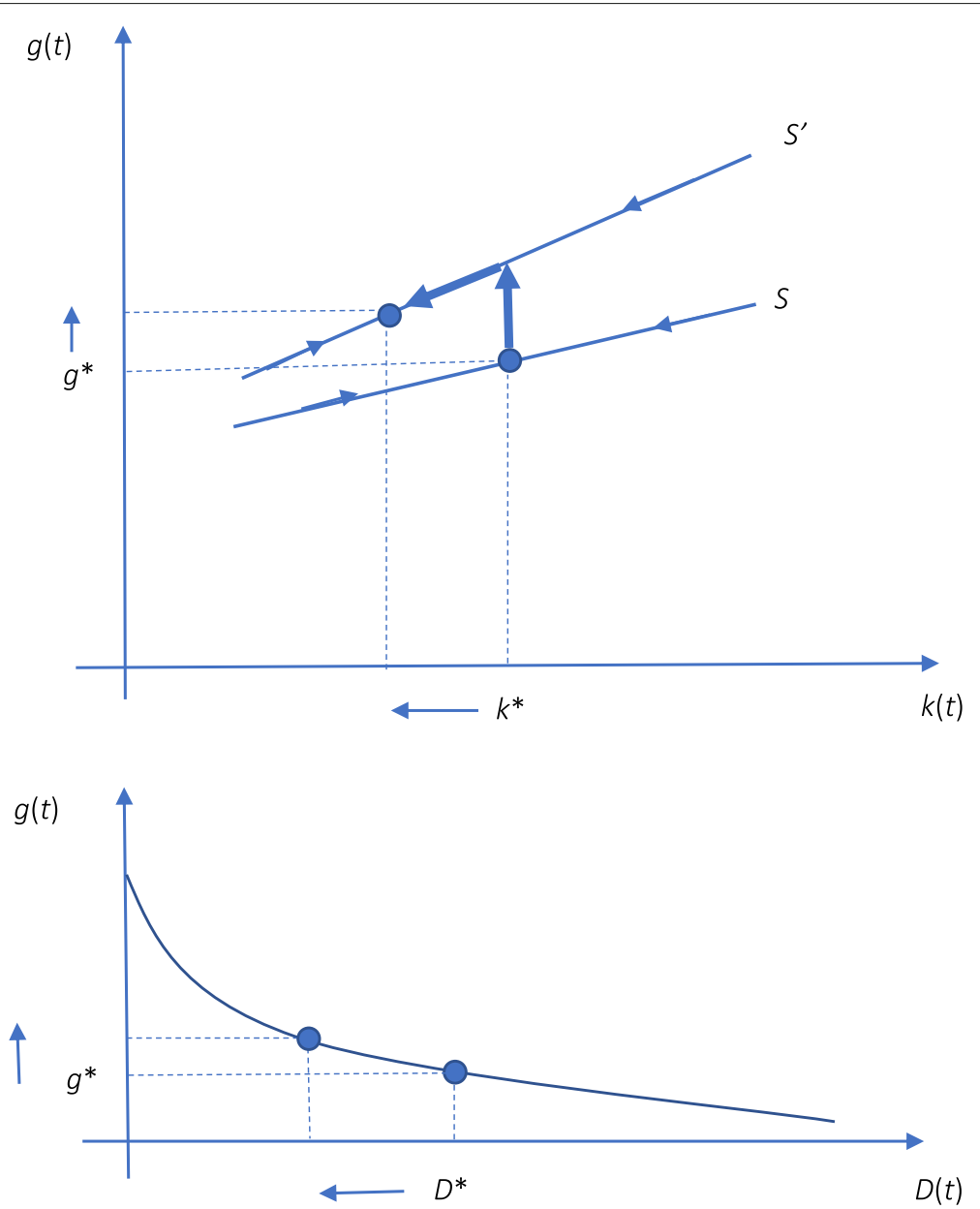

Fig. 5 Steady-state perturbation $\Delta \phi>0$

function $g(t)$ but moves the steady-state equilibrium point to the left; a positive change in the value of $\zeta$ shifts function $g(t)$ down, leading to a fall in $g^{*}$ although maintaining $D^{*}$ in the same equilibrium position.

\section{A two-sector endogenous growth model}

In this section, the previously undertaken analysis is complemented with a modified version of the socially responsible investment model. In the new version, an education sector is added to the framework, and the technology of production of the education sector is considered to be such that the accumulation of human capital is subject to constant marginal returns. The constant returns assumption implies that human capital is the driver of endogenous growth. Because human capital will, then, serve as an input in the development of the investment project, the capital stock of the representative agent will also grow endogenously, in the long-term, at a positive constant rate.

Consider a same objective function as in Eq. (6): the goal of the representative agent continues to be to maximize the returns from investment, i.e., the rate of return multiplied by the capital stock, with these returns duly weighted by the socially responsible behavior, which continues to be measured through control variable $g(t)$. Besides $g(t)$, there is now another control variable, namely the share of human capital allocated to the production process associated with the investment project; let this share be $u(t) \in(0,1)$; its complement, $1-u(t)$, is the fraction of human capital dedicated to the generation of additional human capital via education sector.

The economy has two sectors, that produce physical capital and human capital, respectively. The human capital variable, per labor unit, is defined as $h(t) \geq 0$. The differential equation characterizing the process of accumulation of physical capital is similar to (4), with a meaningful difference: the Cobb-Douglas production function now takes as inputs not only physical capital but also human capital and, therefore, the gross rate of return on investment although continuing to reflect the marginal productivity of capital is now such that 

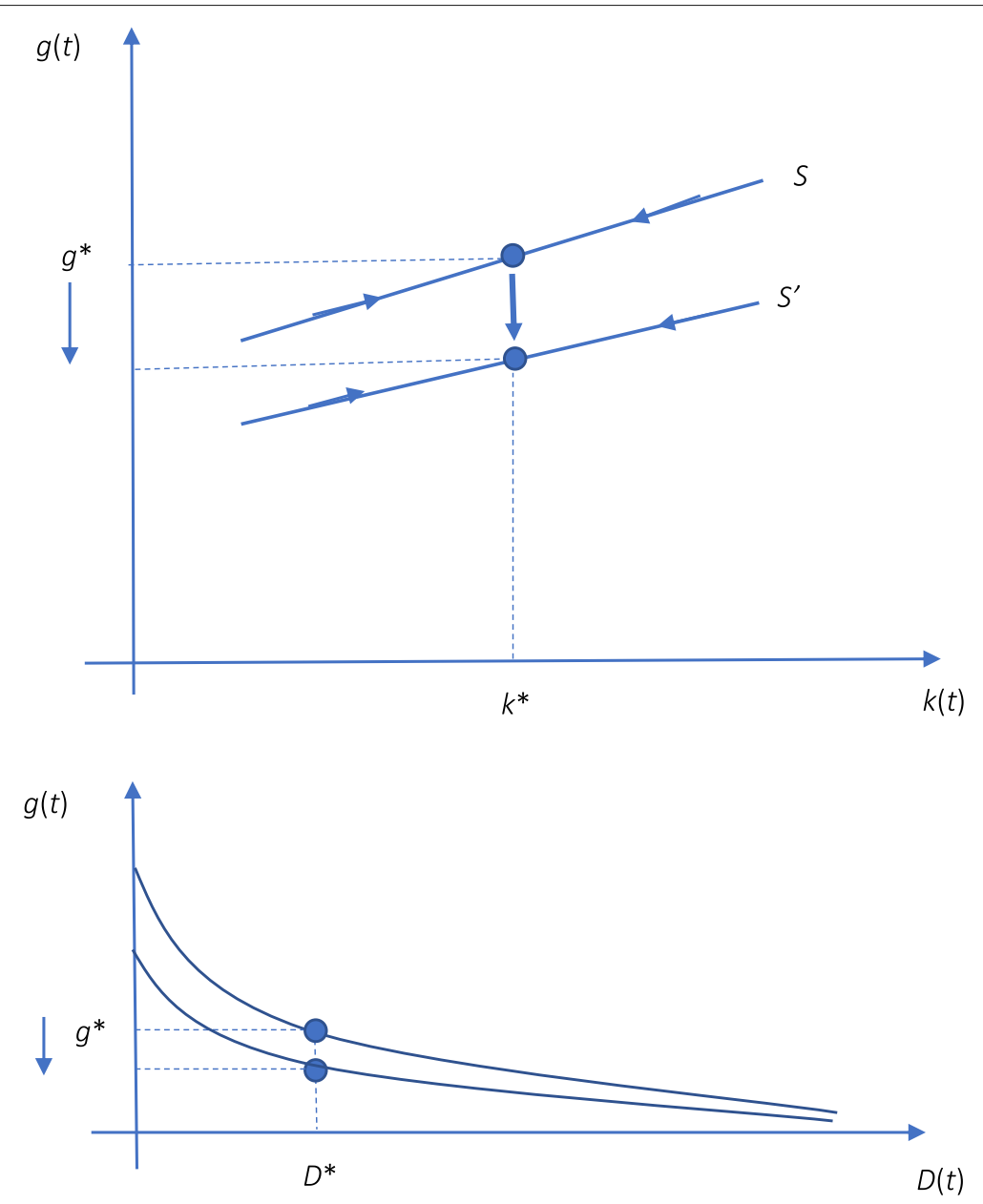

Fig. 6 Steady-state perturbation $\Delta \zeta>0$

$$
r(t)=\alpha A(t)\left[\frac{u(t) h(t)}{k(t)}\right]^{1-\alpha}
$$

The technology variable, $A(t)$, continues to correspond to the expression in (8), since no modification of the social damage impact is being considered; the only addition to the model is the inclusion of a new input that allows for endogenous growth. As stated, the generation of human capital is subject to constant marginal returns, and the respective process of accumulation is given by

$$
\dot{h}(t)=B[1-u(t)] h(t)-\delta h(t), \quad h(0)=h_{0} \text { given, } B>0
$$

Parameter $\delta \in(0,1)$ represents, in this case, the obsolescence or depreciation rate of human capital, which, for a matter of simplification is, in what follows, considered identical to the depreciation rate of $k(t)$.

The characterized optimal control model might be solved as in the simpler version, by setting up the currentvalue Hamiltonian function and by computing first-order conditions. The presentation of the Hamiltonian function requires the definition of two current-value costate variables, associated with each one of the dynamic constraints; let these be, respectively for the physical capital and for the human capital constraints, $p(t)$ and $q(t)^{7}$. Let

$$
\begin{aligned}
H[k(t), h(t), g(t), u(t), p(t), q(t)] & =\{r(t)[g(t)+p(t)]-\delta p(t)\} k(t) \\
& +\{B[1-u(t)]-\delta\} q(t) h(t)
\end{aligned}
$$

\footnotetext{
${ }^{7}$ As before, current-value costate variables contrast with their present-value counterparts. Concerning the first of these variables, we have, as previously assumed, $p(t) \equiv \tilde{p}(t) e^{\rho t}$. Relatively to $q(t)$, because this is associated with the engine of growth, the present-value version of this variable will grow at the constant steady-state growth rate, which for now we designate by $v$. Thus, $q(t) \equiv \widetilde{q}(t) e^{(\rho+v) t}$; with $\widetilde{q}(t)$ the present-value costate variable associated with human capital accumulation. This specificity will have implications in the presentation of the optimality condition regarding the motion of $q(t)$ and also in the shape of the transversality condition. By assuring that the model is solved for the current-value costate variables as presented, one guarantees the determination of a steady-state locus where human capital and physical capital grow at a constant rate, while the other relevant endogenous variables are constant values.
} 
First-order optimality conditions are computed as in the original version of the model. Two of these conditions might be written exactly as in (11) and (12). Besides these, the following are also optimality conditions:

$$
\frac{\partial H[.]}{\partial u(t)}=0 \Rightarrow(1-\alpha) r(t) \frac{k(t)}{u(t) h(t)}[g(t)+p(t)]=B q(t)
$$

$$
\begin{aligned}
\dot{q}(t) & =(\rho+v) q(t)-\frac{\partial H[.]}{\partial h(t)} \Rightarrow \\
\dot{q}(t) & =(\rho+v+\delta) q(t)-(1-\alpha) r(t) \frac{k(t)}{h(t)}[g(t)+p(t)] \\
& -B[1-u(t)] q(t)
\end{aligned}
$$

with $v>0$ the endogenous steady-state growth rate, as already mentioned in footnote 2. Combining static Eq. (33) with dynamic Eq. (34), a simplified rule of motion for variable $q(t)$ is obtained,

$$
\dot{q}(t)=(\rho+v+\delta-B) q(t)
$$

The transversality conditions are $\lim _{t \rightarrow \infty} q(t) e^{-(\rho+v) t} k(t)=0$ (see footnote 2$)$. and

Because, by assumption, $q(t)$ grows at a zero rate in the steady-state, Eq. (35) contains the answer to the question about the rate at which the two assumed forms of capital grow in the long-term. This rate is

$$
v=B-\rho-\delta
$$

Letting $k^{*}$ and $h^{*}$ grow at rate $v$, two relevant steadystate results emerge: $r^{*}=B-\rho$ and $u^{*}=\frac{\rho}{B}$. Note that $B>\rho$ is, in the current context, a necessary condition to guarantee a positive long-term rate of return and an interior solution for $u^{*}$; furthermore, it allows for a steady-state growth rate above $-\delta$. Further steady-state results might be obtained directly from the inspection of optimality conditions, namely after recalling that, in the long-run equilibrium, $\dot{p}(t)=0$. The steady-state level of the warm-glow effect variable is now

$$
g^{*}=\frac{\rho+\delta-\alpha(B-\rho)}{2(\rho+\delta)-\alpha(B-\rho)} \frac{1}{(1-\phi) \zeta}
$$

Result (37) shares some similarities with (15), namely parameters $\phi$ and $\zeta$ influence this result in the exact same way as before. However, because now the long-term equilibrium rate of return $r^{*}$ is not equal to the depreciation rate but to the difference between the education sector technology and the intertemporal discount rate, the outcome is different. Particularly important is that the extent in which education is successful is crucial to determine the degree of social awareness in equilibrium; observe that $\frac{\partial g^{*}}{\partial B}<0$, meaning that more efficient human capital production lowers $g^{*}$, hence reinforcing the responsible investing behavior; the reason for this outcome is intuitive: as the agent is able to accumulate additional human capital, she can partially replace part of the physical capital in production by human capital, and therefore the first becomes less relevant in generating wealth and the agent can afford to be more selective in choosing where to invest.

Additional steady-state results include the equilibrium project's productivity, the physical capital - human capital ratio, and the social damage result. Let $\omega(t) \equiv k(t) / h(t)$; the mentioned outcomes are:

$$
\begin{aligned}
A^{*} & =\frac{\rho+\delta}{2(\rho+\delta)-\alpha(B-\rho)} \frac{A_{l}}{\phi} \\
\omega^{*} & =\frac{\rho}{B}\left(\frac{\alpha A^{*}}{B-\rho}\right)^{1 /(1-\alpha)} \\
D^{*} & =-\ln \left[\frac{\rho+\delta-\alpha(B-\rho)}{2(\rho+\delta)-\alpha(B-\rho)} \frac{1}{(1-\phi)}\right]
\end{aligned}
$$

These results are qualitatively similar to the ones in the original model, namely with regard to the impact of parameters $\phi$ and $\zeta$ over productivity and social damage. Below, one explores further the two-sector socially responsible investment model, by investigating transitional dynamics.

The analysis of the transitional dynamics of the twosector model might be undertaken in a setting with three endogenous variables and respective motion equations. The variables are the capital ratio, $\omega(t)$, the social awareness index, $g(t)$, and the share of human capital allocated to the development of the investment project, $u(t)$. To write the first equation note that, by definition, $\frac{\dot{\omega}(t)}{\omega(t)}=$ $\frac{\dot{k}(t)}{k(t)}-\frac{\dot{h}(t)}{h(t)}$; therefore, it is straightforward to display the differential equation referring to the capital ratio:

$$
\dot{\omega}(t)=\{r(t)-B[1-u(t)]\} \omega(t)
$$

For variable $g(t)$, given the similarity of the first-order conditions regarding the relation between $g(t)$ and $p(t)$, and the equation of motion for $p(t)$, relatively to the benchmark model, the respective equation of motion is equivalent to (14); this can also be presented as

$$
\begin{aligned}
\dot{g}(t)= & \frac{1}{2}\left\{\alpha r(t)\left[\frac{1}{(1-\phi) \zeta}-g(t)\right]\right. \\
& \left.-(\rho+\delta)\left[\frac{1}{(1-\phi) \zeta}-2 g(t)\right]\right\}
\end{aligned}
$$

Finally, an equation of motion for share $u(t)$ is obtainable by differentiating optimality condition (33) with respect to time and, consequently, by replacing the various time derivatives by the respective rules of motion. The outcome is:

$\dot{u}(t)=\left\{\frac{\rho+\delta}{\alpha} \frac{1-2(1-\phi) \zeta g(t)}{1-(1-\phi) \zeta g(t)}-B[1-u(t)]\right\} u(t)$ 
Equations (41), (42), and (43) form a three-variable threedimensional system, for which one can analyze the respective dynamics in the steady-state vicinity. The linearization of each equation conducts to the following matricial system:

$$
\left[\begin{array}{c}
\dot{\omega}(t) \\
\dot{g}(t) \\
\dot{u}(t)
\end{array}\right]=\widehat{J} .\left[\begin{array}{c}
\omega(t)-\omega^{*} \\
g(t)-g^{*} \\
u(t)-u^{*}
\end{array}\right]
$$

with

$$
\widehat{J}=\left[\begin{array}{ccc}
-(1-\alpha)(B-\rho) & -\frac{(B-\rho) \omega^{*}}{(1-\phi) \zeta}-g^{*} & {\left[\alpha+(1-\alpha) \frac{B}{\rho}\right] B \omega^{*}} \\
-\frac{1}{2} \frac{\alpha(1-\alpha)(B-\rho)\left[\frac{1}{1(-\phi) \zeta \zeta}-g^{*}\right]}{\omega^{*}} & (\rho+\delta)-\alpha(B-\rho) & \frac{\alpha}{2} \frac{\alpha(1-\alpha) B(B-\rho)\left[\frac{1}{(1-\phi) \zeta \zeta}-g^{*}\right]}{\rho} \\
0 & -\frac{\rho(\rho+\delta)}{(1-\phi) \zeta} & \rho \\
\alpha B\left[\frac{1}{(1-\phi) \zeta}-g^{*}\right]^{2} & \rho
\end{array}\right]
$$

Despite the dimension of matrix (45) and the complexity of some of its elements, the eigenvalues of $\widehat{J}$ correspond to simple expressions, namely $\lambda_{1}=-(v-\rho), \lambda_{2}=0$, $\lambda_{3}=\rho$. Therefore, the system displays a bifurcation dimension (associated with $\lambda_{2}$ ), an unstable dimension (associated with $\lambda_{3}$ ), and a dimension that might be either stable or unstable (associated with $\lambda_{1}$ ); the condition for the existence of a stable dimension, which guarantees convergence to the steady-state from any initial point near the equilibrium (given that two of the three endogenous variables are control variables), is $v>\rho$.

To obtain further insights from the analysis of transitional dynamics, one computes the eigenvector associated with the negative (under $v>\rho$ ) eigenvalue $\lambda_{1}$ :

$$
\widehat{P}=\left[\begin{array}{c}
1 \\
\frac{\alpha(\rho+\delta)(B-\rho-\delta)}{[2 B-\alpha(B-\rho)][2(\rho+\delta)-\alpha(B-\rho)] \omega^{*}} \frac{1}{(1-\phi) \zeta} \\
\frac{\rho}{B} \frac{2(\rho+\delta)-\alpha(B-\rho)}{2 B-\alpha(B-\rho)] \omega^{*}}
\end{array}\right]
$$

Eigenvector (46) allows for the straightforward presentation of the saddle-path trajectories, which are:

$$
g(t)-g^{*}=\frac{\alpha(\rho+\delta)(B-\rho-\delta)}{[2 B-\alpha(B-\rho)][2(\rho+\delta)-\alpha(B-\rho)] \omega^{*}} \frac{1}{(1-\phi) \zeta}\left[\omega(t)-\omega^{*}\right]
$$

$$
u(t)-u^{*}=\frac{\rho}{B} \frac{2(\rho+\delta)-\alpha(B-\rho)}{[2 B-\alpha(B-\rho)] \omega^{*}}\left[\omega(t)-\omega^{*}\right]
$$

For a positive $v$, both stable trajectories have a positive slope, what signifies that the social awareness discount decreases $[g(t)$ increases] with an increase in the stock of physical capital relatively to human capital; also, the increase in the stock of physical capital relatively to human capital occurs, in the adjustment process to equilibrium, together with a reallocation of human capital in the direction of the productive sector.

\section{Conclusion}

Failing to comply with ethical, moral, or even legal requirements in business may offer a competitive advantage to firms and other project developers relatively to those who allocate resources to the fulfilment of those requirements. In such a scenario, investors will have a dilemma to solve: to be solely concerned with financial returns and disregard how such returns are generated or, alternatively, to be ethically conscientious and, thus, to be prepared to renounce to part of their gain in favor of the satisfaction and tranquility of investing in socially responsible projects. The model developed in this paper considers a heterodox view (i.e., behavioral view) of people's choices and assumes that agents are not solely driven by profitability criteria. If utility comes both from financial gains and from the satisfaction of investing conscientiously, then a trade-off emerges, and this trade-off might be assessed under a dynamic optimal control framework.

The proposed model considers a typical process of utility maximization subject to a capital accumulation constraint under two standard growth environments. In the first setting, the production technology is of the CobbDouglas kind, and therefore we are in the presence of a neoclassical growth setup with zero steady-state growth; the second version of the model is more sophisticated, in the sense that an education sector is added; in the education sector, the production function of human capital exhibits constant marginal returns, thus leading to a scenario of endogenous growth, with both physical capital and human capital growing at a positive constant rate over a balanced growth path.

The analysis concentrates on investment outcomes, and not on consumption-savings decisions, what allows for a more straightforward analysis of the representative agent's options. Basically, the representative investor will desire to act ethically and therefore she will weight ethical behavior against financial returns; given her preference patterns, it is possible to determine the levels of social responsibility, social damage, and financial return that will prevail in the steady-state. Although simple, the model is sufficiently comprehensive to equate and explain how two conflicting investment goals collide and how the agent will make the optimal choice which, in this case, is not a choice that just maximizes financial outcomes but a choice that also answers to the criterion of social responsibility.

The fundamental message that the developed model intends to convey, in either the neoclassical and endogenous growth versions, is synthesized in the graphic of Fig. 7. This graphic displays two lines, both representing the utility level of the investor. The line with a positive slope throughout the entire social damage range is the utility of the financial gain associated with the investment, without any attached social responsibility concern; in this case, the agent is solely focused on the return of the 


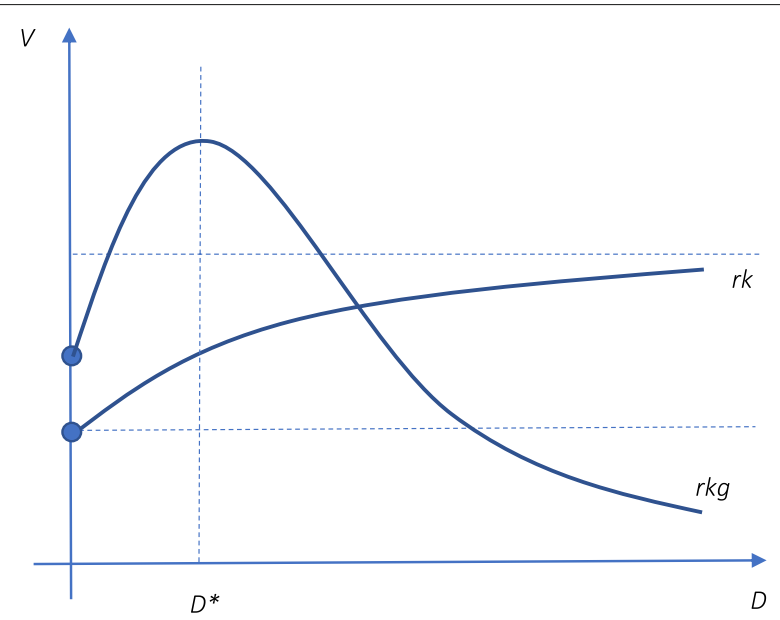

Fig. 7 Utility functions: financial gain vs social responsibility

investment, and she is willing to accept an ever increasing social damage, because, under the model's assumptions, additional social damage is associated with projects delivering higher productivity and higher returns. In this case, the posed problem is not, in fact, a relevant economic problem: there is no constraint preventing the investor of pursuing ever increasing financial gains.

The curve with a maximum value at $D^{*}$ is the utility of the investor when SRI concerns are brought into the agent's deliberation process. In this case, a tradeoff emerges and the problem becomes worth analyzing from an economic analysis point of view. In a first phase, the agent finds it beneficial to invest in projects that are socially more damaging because they have associated a higher return. As the impact of diminishing capital returns gets stronger this desire is changed, because the additional financial gain is overtaken by the social awareness component of the utility function that penalizes investment opportunities leading to stronger ethical, environmental, social and political worries. The utility function that combines the financial gain with the ethical dividend is a function with a maximum, and the rational agent will act in order to attain this maximum. Therefore, the agent in the proposed model remains a rational agent who acts optimally, although her preferences are not orthodox from the mainstream Economics point of view.

Socially responsible behavior is a fundamental topic of analysis in Economics and Finance that scientists are beginning to approach in a systematic and integrated way. Such behavior is an important part of the mechanisms markets and the economy in general have to regulate themselves and to fight negative externalities. Although ethical behavior has always been present in economic relations and perceived as essential for economic transactions to take place and to be successful (recall the moral sentiments thesis of Adam Smith), economists have almost always avoided to take a path that has evident psychological and sociological ramifications. Today, the economic science is mature enough to start to formally address issues that go beyond formal rational choice and formal rational decision-making; SRI undoubtedly falls in this category.

The proposed framework is a toy model, designed essentially to serve as a theoretical guide to think about the courses of action that are available to the investor, who is confronted with the dilemma of serving her own interest, while at the same time supporting and preserving the common good. One might argue that pursuing the common good is a task for the public authorities, and not a direct concern of private investors. However, along the last few years, societies have changed and have placed an enormous pressure on how investors act. Therefore, designing the type of model that this study has proposed is not only a theoretical exercise or a modest contribution to the advancement of the theory; it is also a reminder of how investment decisions are, in practice, prone to be influenced by a wide variety of stakeholders who reflect the society's sentiment in a given economic or political context. Obviously, the analyzed framework was kept simple and it has presented only the most basic structural elements involving an issue that, in its essence, is extremely complex. Further work is needed to refine the analysis and to deepen the understanding of the behavioral underpinnings of investment decisions. Future work might, for instance, concentrate on the indirect reputation gains that come from avoiding social damage and not only on the direct warm-glow effect; while the emotional reward is only felt at the utility level, the reputation gains might have a long-term impact on the ability of the investor to access profitable investment opportunities.

\section{Abbreviations \\ SRI: Socially responsible investment; IDEAS-REPEC: IDEAS - Research papers in economics; TFP: Total factor productivity}

\section{Acknowledgments}

Financial support from the CEFAGE - ISCAL/IPL research center is gratefully acknowledged, under Portuguese Science and Technology Foundation (FCT Fundação para a Ciência e Tecnologia) research project UIDB/04007/2020. I also thank the insightful comments and suggestions of three anonymous referees, which helped in improving the contents of the paper. The usual disclaimer applies.

\section{Authors' contributions}

I am the single author of this study. The author(s) read and approved the final manuscript.

\section{Funding}

Financial support from the CEFAGE - ISCAL/IPL research center was received [Portuguese Science and Technology Foundation (FCT - Fundação para a Ciência e Tecnologia) research project UIDB/04007/2020]

\section{Availability of data and materials}

The paper consists in the formalization, development and discussion of a theoretical model. No empirical data or materials were used in its elaboration. 


\section{Competing interests}

The author declares that he has no competing interests.

\section{Received: 4 May 2020 Accepted: 2 August 2020}

Published online: 08 September 2020

\section{References}

Acemoglu, D., Akcigit, U., Alp, H., Bloom, N., Kerr, W. (2018). Innovation, Reallocation, and Growth. American Economic Review, 108, 3450-3491.

Agudelo, M.A.L., Jóhannsdóttir, L., Davídsd óttir, B. (2019). A Literature Review of the History and Evolution of Corporate Social Responsibility. International Journal of Corporate Social Responsibility, 4, 1-23.

Ainsworth, A., Corbett, A., Satchell, S. (2018). Psychic Dividends of Socially Responsible Investment Portfolios. Journal of Asset Management, 19, 179-190.

Akcigit, U., \& Kerr, W.R. (2018). Growth through Heterogeneous Innovations Journal of Political Economy, 126, 1374-1443.

Altman, M. (2009). A Behavioral-Institutional Model of Endogenous Growth and Induced Technical Change. Journal of Economic Issues, 43, 685-714.

Antoci, A., Russu, P., Sordi, S., Ticci, E. (2012). The Interaction between Natural Resources and Physical Capital-intensive Sectors in a Behavioral Model of Economic Growth. Department of Economics University of Siena working paper $n^{\circ} 661$

Arthur, W.B. (2013). Complexity Economics: a Different Framework for Economic Thought. Santa Fe Institute working paper $n^{\circ}$ 2013-04-012.

Barca, E.-M. (2015). Familiarity of Algerian Investors with Socially Responsible Investment (SRI). International Journal of Management Science and Business Administration, 1, 73-85.

Barro, R.J., \& Sala-i-Martin, X. (2004). Economic Growth, $2^{\text {nd }}$ edition. Cambridge: MIT Press.

Bello, Z.Y. (2005). Socially Responsible Investing and Portfolio Diversification. Journal of Financial Research, 28, 41-57.

Benlemlih, M., \& Bitar, M. (2018). Corporate Social Responsibility and Investment Efficiency. Journal of Business Ethics, 148, 647-671.

Chatzitheodorou, K., Skouloudis, A., Evangelinos, K., Nikolaou, I. (2019). Exploring Socially Responsible Investment Perspectives: a Literature Mapping and an Investor Classification. Sustainable Production and Consumption, 19, 117-129.

Ciciretti, R., Dalò, A., Dam, L. (2017). The Price of Taste for Socially Responsible Investment. CEIS Research Paper 413, Tor Vergata University. https://www. rug.nl/research/portal/publications/the-price-of-taste-for-sociallyresponsible-investment. Accessed 1 Aug 2020

Crifo, P., \& Mottis, N. (2016). Socially Responsible Investment in France. Business \& Society, 55, 576-593.

Dam, L. (2011). Socially Responsible Investment in an Environmental Overlapping Generations Model. Resource and Energy Economics, 33, 1015-1027.

Dam, L., \& Heijdra, B. (2011). The Environmental and Macroeconomic Effects of Socially Responsible Investment. Journal of Economic Dynamics and Control, 35, 1424-1434.

Dam, L., \& Scholtens, B. (2015). Toward a Theory of Responsible Investing: on the Economic Foundations of Corporate Social Responsibility. Resource and Energy Economics, 41, 103-121.

Dias Curto, J., \& Vital, C. (2014). Socially Responsible Investment: a Comparison between the Performance of Sustainable and Traditional Stock Indexes. Journal of Reviews on Global Economics, 3, 349-363.

Diez-Canamero, B., Bishara, T., Otegi-Olaso, J.R., Minguez, R., Fernández, J.M. (2020). Measurement of Corporate Social Responsibility: a Review of Corporate Sustainability Indexes, Rankings and Ratings. Sustainability, 12, $1-36$.

Fama, E., \& French, K.R. (2007). Disagreement, Tastes, and Asset Prices. Journal of Financial Economics, 83, 667-689.

Gil-Bazo, J., Ruiz-Verdú, P., Santos, A. (2010). The Performance of Socially Responsible Mutual Funds: the Role of Fees and Management Companies. Journal of Business Ethics, 94, 243-263.

Ghoul, S., \& Karoui, A. (2017). Does Corporate Social Responsibility Affect Mutual Fund Performance and Flows? Journal of Banking \& Finance, 77, 53-63.

Grossman, G.M., \& Helpman, E. (2018). Growth, Trade, and Inequality. Econometrica, 86, 37-83.

Häfner, D., Kiesel, F., Wirthmann, L. (2017). What do We Know about Socially Responsible Investments? Darmstadt Technical University Institute for Business Studies (BWL) 90075
Holt, R.P.F., Rosser, J.B., Colander, D. (2011). The Complexity Era in Economics. Review of Political Economy, 23, 357-369.

Jaimovich, N., \& Rebelo, S. (2017). Nonlinear Effects of Taxation on Growth. Journal of Political Economy, 125, 265-291.

Jones, C.I. (2016). Life and Growth. Journal of Political Economy, 124, 539-578.

Kaplan, G., Violante, G.L., Weidner, J. (2014). The Wealthy Hand-to-Mouth. NBER working paper $\mathrm{n}^{\circ} 20073$

Kim, Y.J., \& Song, J. (2014). Romer Meets Heterogeneous Workers in an Endogenous Growth Model. Hitotsubashi Journal of Economics, 55, 121-146.

Klobukowska, J. (2017). Socially Responsible Investment in Asia. Copernican Journal of Finance \& Accounting, 6, 55-65.

Knuutinen, R., \& Pietiläinen, M. (2017). Responsible Investment: Taxes and Paradoxes. Nordic Tax Journal, 2017, 135-150.

Lapanan, N. (2018). The Investment Behavior of Socially Responsible Individual Investors. Quarterly Review of Economics and Finance, 70, 214-226.

Latinovic, M., \& Obradovic, T. (2013). The Performance of Socially Responsible Investments. Entrepreneurial Business and Economics Review, 1, 29-40.

Lean, H.H., Ang, W.R., Smyth, R. (2015). Performance and Performance Persistence of Socially Responsible Investment Funds in Europe and North America. North American Journal of Economics and Finance, 34, 254-266.

López-Arceiz, F.J., Bellostas-Pérezgrueso, A.J., Moneva, J.M. (2018). Evaluation of the Cultural Environment's Impact on the Performance of the Socially Responsible Investment Funds. Journal of Business Ethics, 150, 259-278.

Lozano, J., Albareda, L., Balaguer, M. (2006). Socially Responsible Investment in the Spanish Financial Market. Journal of Business Ethics, 69, 305-316.

Lucas, R.E. (1988). On the Mechanics of Economic Development. Journal of Monetary Economics, 22, 3-42

Miralles-Quirós, M.M., \& Miralles-Quirós, J.L. (2017). Improving Diversification Opportunities for Socially Responsible Investors. Journal of Business Ethics, $140,339-351$.

Nakai, M., Honda, T., Nishino, N., Takeuchi, K. (2013). An Experimental Study on Motivations for Socially Responsible Investment. Discussion Papers 1314 Graduate School of Economics, Kobe University.

Oikonomou, I., Platanakis, E., Sutcliffe, C. (2018). Socially Responsible Investment Portfolios: Does the Optimization Process Matter?|. British Accounting Review, 50, 379-401.

Pérez-Gladish, B., Benson, K., Faff, R. (2012). Profiling Socially Responsible Investors: Australian Evidence. Australian Journal of Management, 37, 189-209.

Petrillo, A., de Felice, F., García-Melón, M., P. érez-Gladish, B. (2016). Investing in Socially Responsible Mutual Funds: Proposal of Non-financial Ranking in Italian Market. Research in International Business and Finance, 37, 541-555.

Pouget, S. (2014). On the Financial Performance of Socially Responsible Investments. Bankers, Markets \& Investors, 128, 31-35.

Puaschunder, J.M. (2017). Socio-Psychological Motives of Socially Responsible Investors. Advances in Financial Economics Global Corporate Governance, 19, 209-247.

Rathner, S. (2012). The Performance of Socially Responsible Investment Funds: a Meta-Analysis. Working papers in Economics 2012-3, University of Salzburg. http://www.uni-salzburg.at/fileadmin/oracle_file_imports/ 1759214.PDF. Accessed 1 Aug 2020

Rathner, S. (2013). The Relative Performance of Socially Responsible Investment Funds. New Evidence from Austria. Working papers in Economics 2013-1, University of Salzburg. http://www.uni-salzburg.at/ fileadmin/oracle file imports/2133616.PDF. Accessed 1 Aug 2020.

Renström, T., \& Spataro, L. (2018). Optimal Taxation, Environment Quality, Socially Responsible Firms and Investors. Discussion Papers 2018/232 Dipartimento di Economia e Management (DEM), University of Pisa, Pisa, Italy. https://www.ec.unipi.it/documents/Ricerca/papers/2018-232.pdf. Accessed 1 Aug 2020.

Revelli, C. (2017). Socially Responsible Investing (SRI): from Mainstream to Margin? Research in International Business and Finance, 39, 711-717.

Revelli, C., \& Viviani, J.L. (2015). Financial Performance of Socially Responsible Investing (SRI): What Have We Learned? A Meta-Analysis. Business Ethics: A European Review, 24, 158-185

Risalvato, G. (2017). Investments in Ethical Funds and Indices: an Overview of Performance, 031815. SSRN working paper 3.

Risalvato, G., Venezia, C., Maggio, F. (2019). Social Responsible Investments and Performance. International Journal of Financial Research, 10, 10-16.

Romer, P.M. (1990). Endogenous Technological Change. Journal of Political Economy, 98, S71-S102 
Rossi, M., Sansone, D., van Soest, A., Torricelli, C. (2019). Household Preferences for Socially Responsible Investments. Journal of Banking \& Finance, 105, $107-120$.

Sakuma, K., \& Louche, C. (2008). Socially Responsible Investment in Japan: Its Mechanism and Drivers. Journal of Business Ethics, 82, 425-448.

Shiller, R.J. (2015). Irrational Exuberance. Princeton: Princeton University Press. Sliwinski, P., \& Lobza, M. (2017). Financial Performance of Socially Responsible Indices. International Journal of Management and Economics, 53, 25-46.

Tamvada, M. (2020). Corporate Social Responsibility and Accountability: a New Theoretical Foundation for Regulating CSR. International Journal of Corporate Social Responsibility, 5, 1-14.

Thaler, R.H. (2015). Misbehaving: the Making of Behavioral Economics. New York: W.W. Norton \& Company.

Torres, O.T., \& Enciso, M.I.M.T. (2017). Is Socially Responsible Investment Useful in Mexico? A Multi-factor and Ex-ante Review. Contaduría y Administración, Accounting and Management, 62, 222-238.

Tosun, O.K. (2017). Is Corporate Social Responsibility Sufficient Enough to Explain the Investment by Socially Responsible Funds?. Review of Quantitative Finance and Accounting, 49, 697-726.

van Dooren, B., \& Galema, R. (2018). Socially Responsible Investors and the Disposition Effect. Journal of Behavioral and Experimental Finance, 17, 42-52.

Zeira, J., \& Zoabi, H. (2015). Economic Growth and Sector Dynamics. European Economic Review, 79, 1-15.

\section{Publisher's Note}

Springer Nature remains neutral with regard to jurisdictional claims in published maps and institutional affiliations.

\section{Submit your manuscript to a SpringerOpen ${ }^{\circ}$ journal and benefit from:}

- Convenient online submission

- Rigorous peer review

- Open access: articles freely available online

- High visibility within the field

- Retaining the copyright to your article

Submit your next manuscript at $\gg$ springeropen.com 